\section{ScienceDirect}

Materials Today: Proceedings 13 (2019) 698-705 materialstoday:
PROCEEDINGS

www.materialstoday.com/proceedings

\title{
New polymer inclusion membrane containing NTA as carrier for the recovery of chromium and nickel from textiles wastewater
}

\author{
Y.Chaouqi ${ }^{\mathrm{a}, \mathrm{b} *}$, R. Ouchn ${ }^{\mathrm{a}, \mathrm{b}}$, T. Eljaddi ${ }^{\mathrm{a}}$, A. Jada ${ }^{\mathrm{c}}$, M. El bouchti ${ }^{\mathrm{b}}$, \\ O. Cherkaoui ${ }^{\text {b }, M . ~ H l a i b i ~}{ }^{\mathrm{a}}$ \\ ${ }^{a}$ Laboratoire Génie des Matériaux pour Environnement et Valorisation (GeMEV), Faculté des Sciences Ä̈n Chock, Université Hassan II, \\ Casablanca, Morocco \\ ${ }^{b}$ Laboratoire de Recherche sur les Matériaux Textiles (REMTEX), ESITH Casablanca, Morocco \\ ${ }^{c}$ Institut de Sciences Des Matériaux De Mulhouse (IS2M-UMR 7361 CNRS - UHA) 15 rue Jean Starcky 68057-Mulhouse, France
}

\begin{abstract}
Extraction and/or recovery of chromium $(\mathrm{Cr})$ and nickel $(\mathrm{Ni})$ from textiles industry wastewater by membrane separation using polymer inclusion membranes (PIMs) based on polymer supports polyvinylidene fluoride (PVDF) and polyvinyl pyrrolidone (PVP), with Nitrilotriacetic acid (NTA) as extractive agent (EA). Furthermore, to quantify the PIMs performances, the macroscopic parameters such as the membrane permeability, $\mathrm{P}$, and the initial flux, $\mathrm{J}_{0}$, and the microscopic parameters such as the association constant, Kass, and the apparent diffusion coefficient, $\mathrm{D}^{*}$, were determined based on the Fick's first law and the saturation law of the EA by the substrate (S). Also, to explain the substrate $(\mathrm{S})(\mathrm{Cr}$ or Ni) recovery process performed by the membrane, and to elucidate the mechanistic aspects, the activation parameters such as the energy Ea, the enthalpy $\Delta \mathrm{H}^{\neq}$and the entropy $\Delta \mathrm{S}^{\ddagger}$, were determined. The efficiency of different PIMs to recover $\mathrm{Cr}$ and Ni was compared. Respectively, the influence of temperature and $\mathrm{pH}$ on removal performance was investigated. The results showed that the macroscopic and microscopic parameters increased with increasing temperature and acidity medium. Similarly, the values of the activation parameters make it possible to explain the membrane performance and to elucidate the mechanism relating to the diffusion of the extracted substrates through this membrane.
\end{abstract}

(C) 2019 Elsevier Ltd. All rights reserved.

Peer-review under responsibility of the scientific committee of the International Conference on Materials and Environmental Science, ICMES 2018.

Keywords: Extraction; Textiles; Membrane; Chromium; Nickel

* Corresponding author. Tel.:+212522230680; fax:+212522230674.

E-mail address: chaouqi.youssef@gmail.com

2214-7853 @ 2019 Elsevier Ltd. All rights reserved.

Peer-review under responsibility of the scientific committee of the International Conference on Materials and Environmental Science, ICMES 2018. 


\section{Introduction}

Textile industries, and more particularly dyeing and finishing phases, mainly use harmful chemicals for health, and cause pollution of surface water and groundwater. The use of mordant dyes in these industries is a source of metal pollution since they generally contain functional ligands able to react strongly with chromium, nickel, aluminum, cobalt, copper or iron salts, and to yield different colored complexes with the textile. The wastewater resulting from the dyeing, the finishing and the rinsing phases of the dyed textile fibers, contains large amount of dyes and trace metals such as chromium, nickel, aluminum, cobalt, copper or iron ions. It is therefore essential to treat the textile effluents before their release in the aquatic systems.

Most heavy metals are toxic and harmful to living organisms even at lower concentrations [1], they caused the most serious environmental problems. Faced with increasingly strict regulations, these toxic heavy metals should be removed from wastewater to protect people and the environment. Much has been reported on treatment of heavy metal ions include chemical precipitation [2-3], ion exchange [4], adsorption [5-6], membrane filtration [7], electrochemistry processing technologies [8], etc.

One efficient method to extract and/or to recover trace metals from textiles industry wastewater is based on the use of membrane separation processes. Thus, in the present work, we will focus on the use of polymer inclusion membranes (PIMs) which consist of polymer supports such as polyvinylidene fluoride (PVDF) and polyvinyl pyrrolidone (PVP), and an extractive agent (EA) such as Nitrilotriacetic acid (NTA) (Fig.1). Furthermore, to quantify the PIMs performances, the macroscopic parameters, membrane permeability $\mathrm{P}$, and initial flux $\mathrm{J}_{0}$, and the microscopic parameters, association constant Kass, and apparent diffusion coefficient $\mathrm{D}^{*}$, were determined based on the Fick's first law and a saturation law of the EA by the substrate (S). Also, to explain the substrate (S) (Cr or Ni) recovery process performed by the membrane, and to elucidate the mechanistic aspects, the activation parameters, energy Ea, enthalpy $\Delta \mathrm{H}^{\neq}$and the entropy $\Delta \mathrm{S}^{\neq}$, were determined. The efficiencies, of different PIMs to recover $\mathrm{Cr}$ and $\mathrm{Ni}$, were compared. In addition, the influence of the temperature and the $\mathrm{pH}$ factors on the removal performance was also investigated.

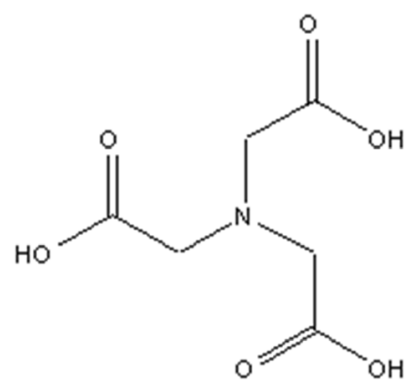

Fig. 1. Structure of extractive agent Nitrilotriacetic acid (NTA).

\section{Material and Methods}

\subsection{Calculations}

Permeability $\mathrm{P}$ and initial flux $\mathrm{J}_{0}$ are calculated from the following relationships [9-10] :

$$
\begin{aligned}
& \mathrm{P}(\mathrm{t}-\mathrm{tL})=(\ell * \mathrm{~V} / 2 * \mathrm{~S}) \ln \left(\mathrm{C}_{0} / \mathrm{C}_{0}-2 \mathrm{C}_{\mathrm{r}}\right) \\
& \mathrm{P}=\mathrm{a}^{*} \mathrm{~V} * \ell / 2 * \mathrm{~S} \text { and } \mathrm{J}_{0}=\mathrm{P} * \mathrm{C}_{0} / \ell
\end{aligned}
$$

a: the slope experimental values of the straight lines $-\operatorname{Ln}\left(C_{0}-2 C_{r}\right)=f(t)$. $\ell$ : the membrane thickness. S: the membrane active area in contact with the aqueous solutions. V: the receiving phase volume. The microscopic parameters Kass and $\mathrm{D}^{*}$ are determinate according to the following relationships:

$$
\begin{aligned}
& 1 / \mathrm{J}_{0}=1 / \mathrm{D}^{*}\left(\left(1 /[\mathrm{T}]_{0} * \text { Kass } * \mathrm{C}_{0}\right)+1 /[\mathrm{T}]_{0}\right) \\
& \text { Kass }=\text { intercept }(\mathrm{oo}) / \text { slope }(\mathrm{p}) \text { and } \mathrm{D}^{*}=(1 / \mathrm{oo}) *\left(1 / /[\mathrm{T}]_{0}\right)
\end{aligned}
$$


With $\mathrm{p}$ and $\mathrm{OO}$ are slope and intercept experimental values of the straight line $1 / \mathrm{J}_{0}=\mathrm{f}\left(1 / \mathrm{C}_{0}\right)$, $[\mathrm{T}]_{0}$ : the fixed total concentration of the extractive agent in the membrane phase.

\subsection{Chemicals}

All chemicals, reagents, and solvents were pure commercial products (Aldrich, Fluka) of analytical grade. The used polymeric support is Polyvinylidene Fluoride PVDF supplied by Alfa Aesar.

\subsection{Extraction experiments}

Kinetic studies relating to the studied process were carried out in a device with two feed and receiving glass compartments [10-12]. The adopted membrane was clamped tightly between these compartments, using two Teflon rings. The cell was immersed in a thermostatic bath with magnetic stirring of the two compartments. Aliquots (about $0.1 \mathrm{~cm}^{3}$ each) of the aqueous receiving phase were withdrawn periodically, analyzed, and their concentrations of the substrate (S) were determined by ultraviolet-visible spectroscopy.

\section{Results and discussion}

\subsection{Characterization of the developed membranes by FTIR}

The two synthesized PIM membranes were characterized by FTIR (Fig. 2), one membrane containing only the PVDF as a base polymer, and the second PIM made of a mixture of PVDF, PVP as a base polymer and containing NTA as EA (5\% M/M). As can be shown in Fig 2; the peaks observed in the spectrum of the PVDF membrane are characteristics of the polymer, namely: a band at $1404 \mathrm{~cm}^{-1}$ assigned to groups $\mathrm{CH}$, a band at $876 \mathrm{~cm}^{-1}$ allocated to the vibration of the linear C-C link and bands occurring between 1074 and $1278 \mathrm{~cm}^{-1}$ corresponding to the elongation vibrations of the C-F connections. The spectrum of the PVDF membrane-NTA shows that most of the absorption bands are present in the spectrum of the PVDF membrane, with the appearance of a characteristic band of the group $\mathrm{C}=\mathrm{O}$ and $\mathrm{O}-\mathrm{H}$ group, present in the molecule of NTA, at $1650 \mathrm{~cm}^{-1}$ and at $3350 \mathrm{~cm}^{-1}$.

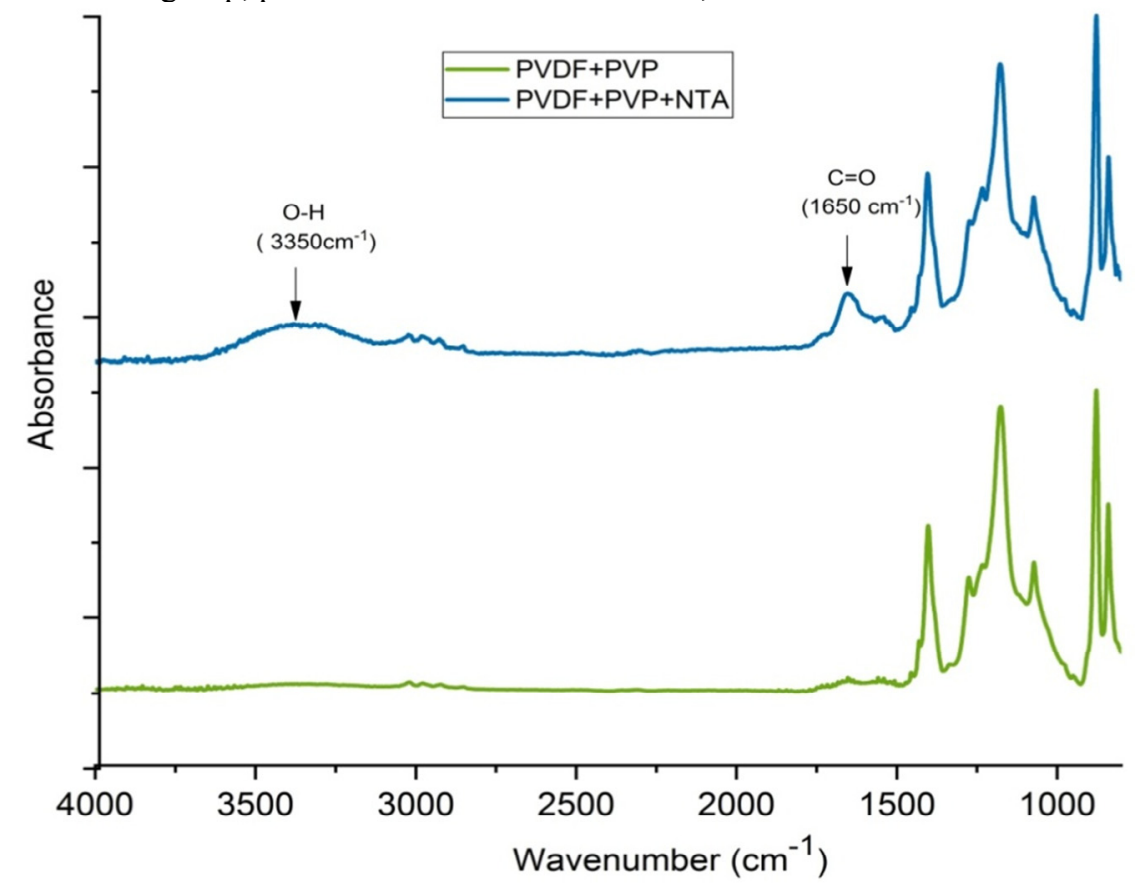

Fig. 2. Fourier transform infrared-attenuated total reflection spectra of the membranes, PVDF support and PVDF-NTA.

\subsection{Characterization of the elaborated membranes by SEM}

The figs. 3 and 4 show the surface and cross-section SEM images of the developed PVDF-NTA membrane. The images clearly show the porous structure relative to an asymmetric and dense membrane. 


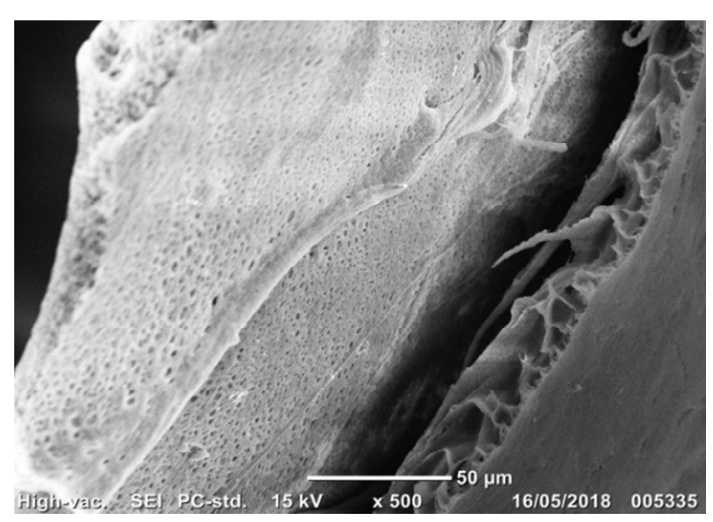

Fig. 3. SEM image PVDF-NTA cross- section.

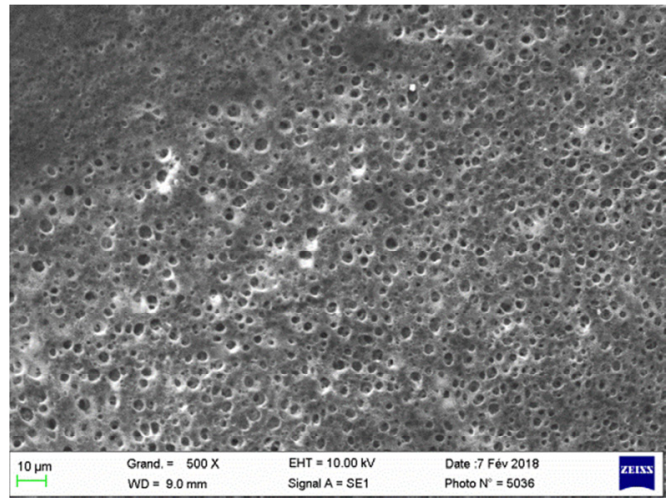

Fig. 4. SEM image PVDF-NTA surface.

\subsection{Effect of initial substrate concentration $\mathrm{CO}$ on the extraction of $\mathrm{Cr}(\mathrm{VI})$ and $\mathrm{Ni}(\mathrm{II})$ ions}

For this part, we examined the influence of the substrate initial concentration $\mathrm{C}_{0}$, on the evolution of various parameters related to the facilitated extraction process of $\mathrm{Cr}(\mathrm{VI})$ and $\mathrm{Ni}(\mathrm{II})$ through the PIM membrane (PVDFNTA) with NTA as extractive agent. The $C_{0}$ initial concentration values varied, from 0.5 to $2 \mathrm{~g} / \mathrm{L}$ and from 3 to 24 $\mathrm{g} / \mathrm{L}$, respectively for $\mathrm{Cr}(\mathrm{VI})$ and $\mathrm{Ni}(\mathrm{II})$ ions, under similar operating conditions ( $\mathrm{pH}=4, \mathrm{~T}=298 \mathrm{~K}$, support: $\mathrm{PVDF}$ ). The evolutions of the kinetic function $-\operatorname{Ln}\left(\mathrm{C}_{0}-2 \mathrm{C}_{\mathrm{r}}\right)=\mathrm{f}(\mathrm{t})$, are presented by the figures 5 and 6 .

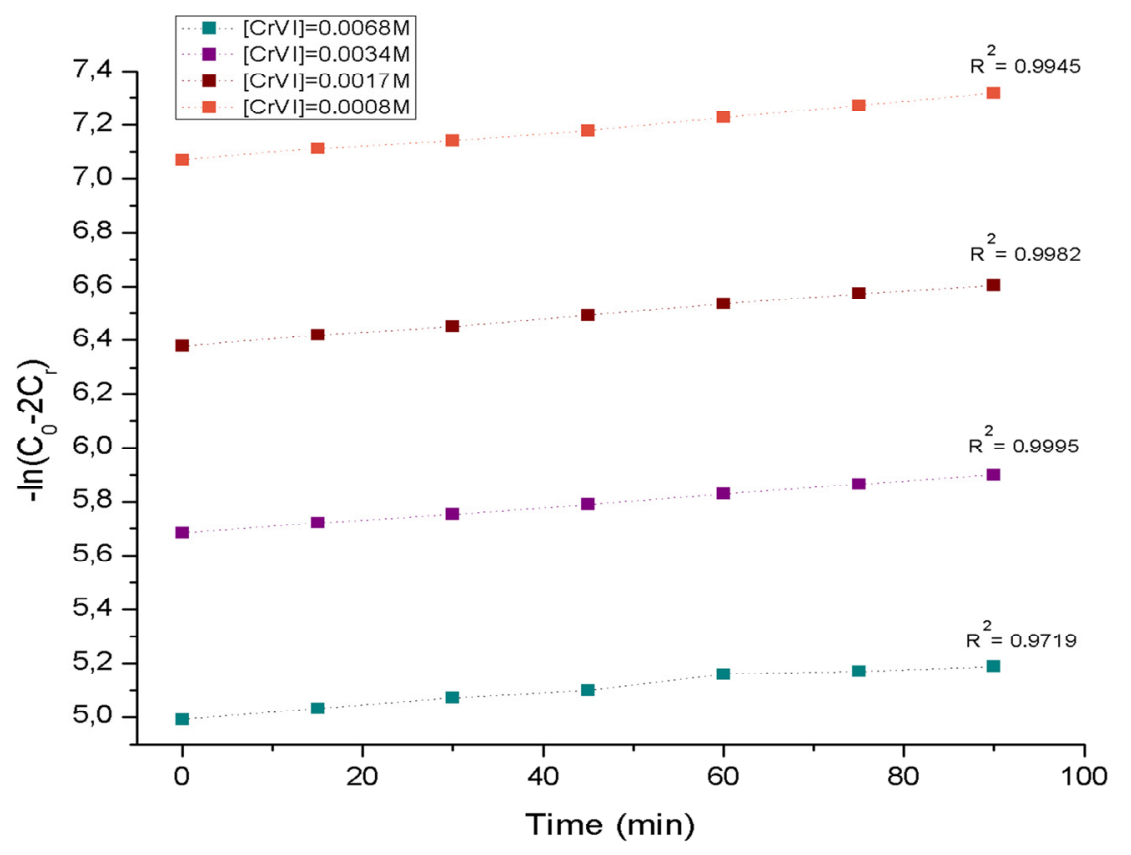

Fig. 5. Evolution of the kinetic function $-\mathrm{Ln}(\mathrm{C} 0-2 \mathrm{Cr})=\mathrm{f}(\mathrm{t})$ for the facilitated extraction of $\mathrm{Cr}(\mathrm{VI})$ for different substrate initial concentrations. [NTA] $0=0.00039 \mathrm{M}, \mathrm{pH}=4$, and $\mathrm{T}=298 \mathrm{~K}$. 


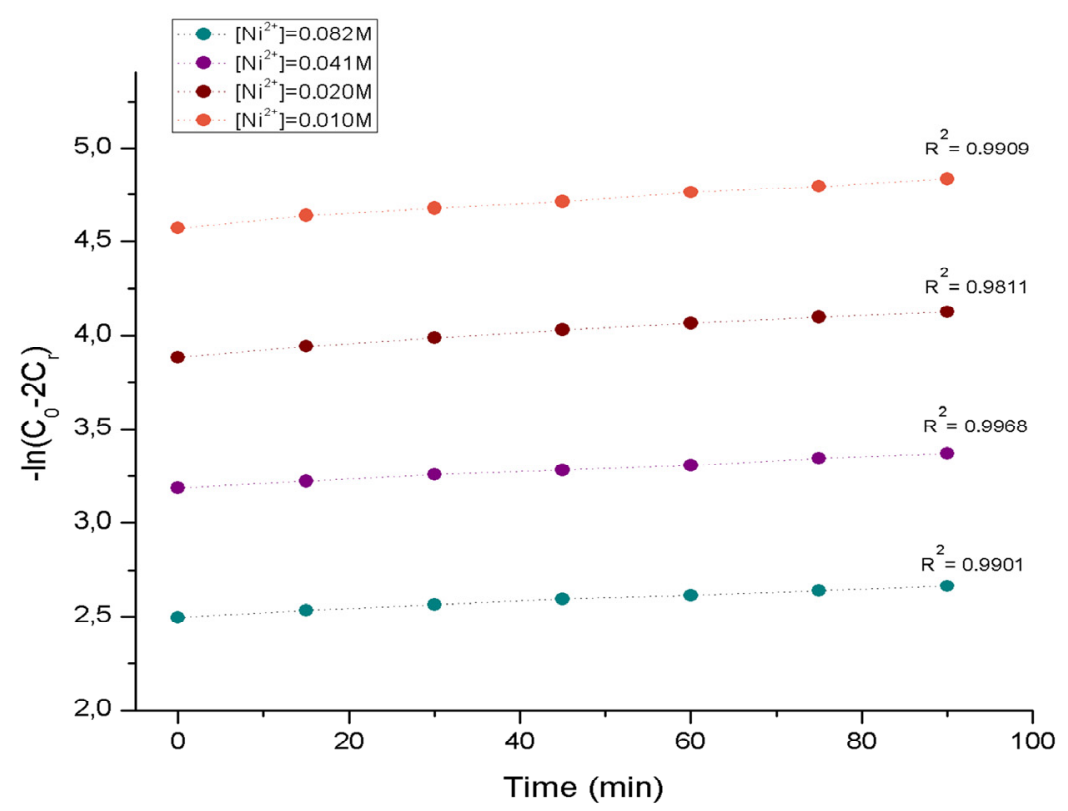

Fig. 6. Evolution of the kinetic function $-\mathrm{Ln}(\mathrm{C} 0-2 \mathrm{Cr})=\mathrm{f}(\mathrm{t})$ for the facilitated extraction of $\mathrm{Ni}(\mathrm{II})$ for different initial substrate concentrations.

$[\mathrm{NTA}] 0=0.0001 \mathrm{M}, \mathrm{pH}=4$, and $\mathrm{T}=298 \mathrm{~K}$.

From the graphs depicted in Figs 5 and 6, we clearly see linear straight lines of the variation of $-\operatorname{Ln}\left(\mathrm{C}_{0}-2 \mathrm{C}_{\mathrm{r}}\right)$ versus time, for both substrates. From the slopes of these straight lines, the values of $\mathrm{P}$ and $\mathrm{J}_{0}$ parameters were calculated and are presented in Table 1:

Table 1. Influence of extractive agent nature and initial substrate concentration $\mathrm{C} 0$ on the evolution of $\mathrm{P}$ and $\mathrm{J} 0 \mathrm{parameters,} \mathrm{pH}=4$, and $\mathrm{T}=298 \mathrm{~K}$

\begin{tabular}{cccc}
\hline Extractive agent & $\begin{array}{c}\text { Initial substrate concentration, } \mathrm{C}_{0} \\
\left(\mathrm{~mol} \mathrm{~L}^{-1}\right)\end{array}$ & $\begin{array}{c}\mathrm{P} \times 10^{-7} \\
\left(\mathrm{~cm}^{2} \mathrm{~s}^{-1}\right)\end{array}$ & $\begin{array}{c}\mathrm{J}_{0} \times 10^{-7} \\
\left(\mathrm{mmol} \mathrm{cm}^{2} \mathrm{~s}^{-1}\right)\end{array}$ \\
\hline \multirow{3}{*}{$\mathrm{Cr}(\mathrm{VI})$} & 0.0068 & 19.27 & 12.96 \\
\cline { 2 - 4 } & 0.0034 & 20.22 & 6.8 \\
\cline { 2 - 4 } & 0.0017 & 21.84 & 3.67 \\
\hline & 0.00085 & 22.89 & 1.92 \\
\hline & 0.0825 & 12.59 & 141.91 \\
\hline & 0.0412 & 14.21 & 80.06 \\
\hline & 0.0206 & 18.33 & 51.63 \\
\hline & 0.0103 & 19.40 & 27.32 \\
\hline
\end{tabular}

All values in Tab. 1 indicate a clear influence of the nature of the extractive agent and a weak influence of the initial substrate concentration, $\mathrm{C}_{0}$, on the evolution of $\mathrm{P}$ and $\mathrm{J}_{0}$ parameters compared with the performance of the adopted PIM. However, the PIM-NTA membrane appears to be relatively more efficient for the facilitated extraction process of $\mathrm{Cr}(\mathrm{VI})$ compared to its $\mathrm{Ni}(\mathrm{II})$ counterpart under the adopted conditions. To establish more accurate interpretations and comparisons of the performance of this membrane type for this oriented process, Line weaver-Burk plots for the function $1 / \mathrm{J}_{0}=\mathrm{f}\left(1 / \mathrm{C}_{0}\right)$ were studied (Figs. 7 and 8 ), in order to calculate and analyze the evolution of microscopic parameters Kass and $\mathrm{D}^{*}$ to the diffusion and the movement of the substrate across the membrane phase. 


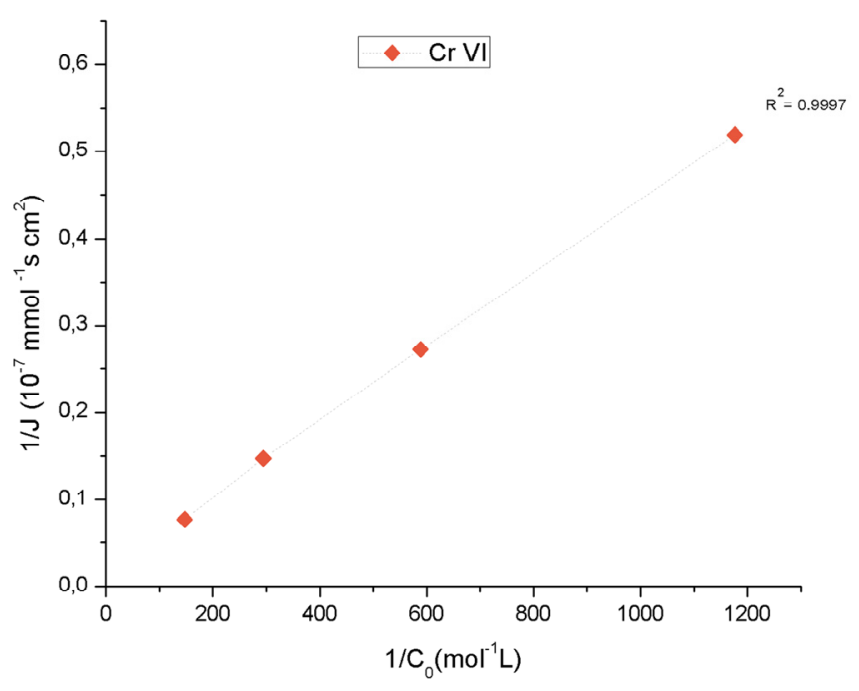

Fig. 7. Line weaver - Burk straights for the facilitated extraction phenomenon of Cr(VI) by the PIM (PVDF-NTA) $[\mathrm{NTA}] 0=0.00387 \mathrm{M}, \mathrm{pH}=4$, and $\mathrm{T}=298 \mathrm{~K}$.

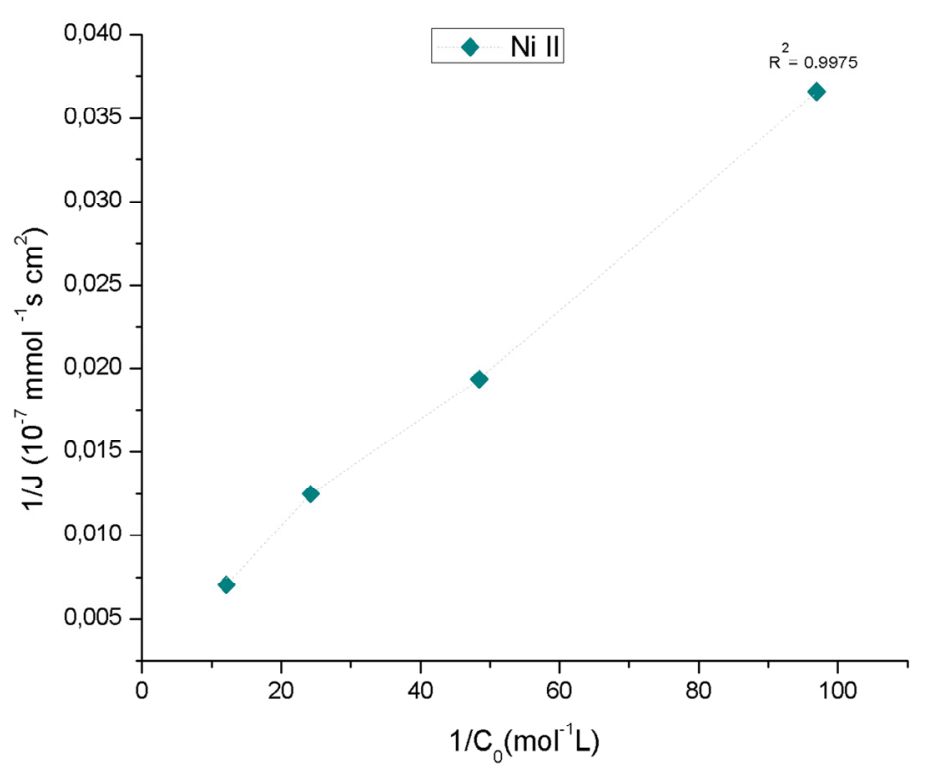

Fig. 8. Line weaver - Burk straights for the facilitated extraction phenomenon of Ni(II) by the PIM (PVDF-NTA) $[\mathrm{NTA}] 0=0.01568 \mathrm{M}, \mathrm{pH}=4$, and $\mathrm{T}=298 \mathrm{~K}$.

The values of the slopes and intercepts of the obtained line segments in Figs. 7 and 8 make it possible to determine the parameters Kass and D* and all obtained values are grouped in Fig 9. 


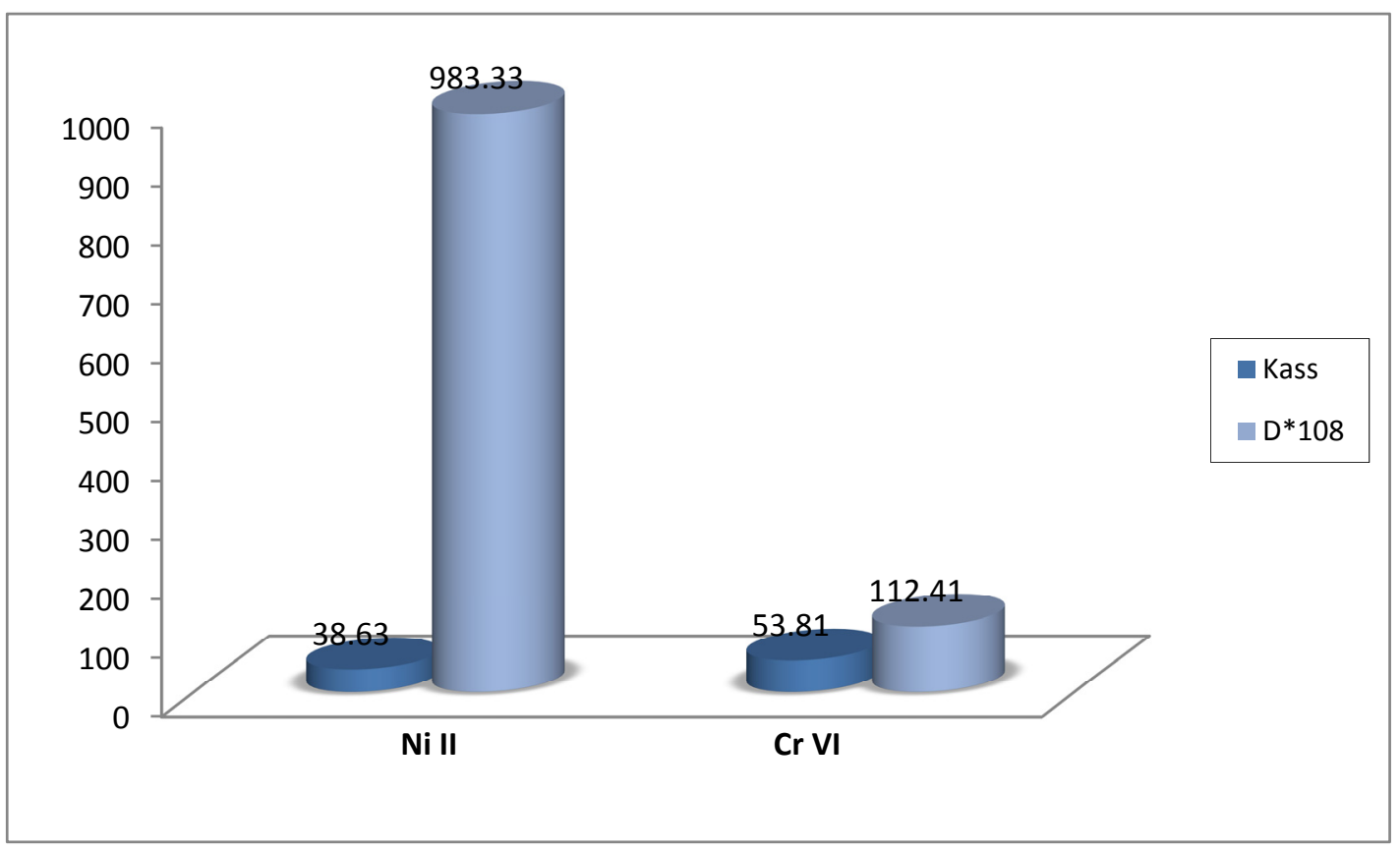

Fig. 9. Evolution graphical representation of the microscopic parameters $\mathrm{D}^{*}$ and Kass relating to facilitated extraction of $\mathrm{Cr}(\mathrm{VI})$ and $\mathrm{Ni}(\mathrm{II})$ by the PIM (PVDF-NTA).

Analysis the graph in Fig 9 confirms that the PIM-NTA membrane is more efficient for the facilitated extraction of $\mathrm{Ni}(\mathrm{II})$ in comparison to the extraction of the $\mathrm{Cr}(\mathrm{VI})$. This difference in behaviour is explained by the different values of apparent diffusion coefficient $\mathrm{D}^{*}$ for the two ions. This analysis confirms that the parameters $\mathrm{D}^{*}$ and Kass are specific for each adopted substrate type. The data are certainly related to the structure of the extractive agent NTA which possesses several possible interaction sites, interacting preferentially with the $\mathrm{Ni}(\mathrm{II})$ ions substrate, in comparison to the $\mathrm{Cr}(\mathrm{VI})$ ions. Consequently, the diffusion of the substrate through the membrane phase according to a mechanism by jumps on fixed sites is more favourable in the presence of $\mathrm{Ni}(\mathrm{II})$ than its $\mathrm{Cr}(\mathrm{VI})$ counterpart.

\section{Conclusion}

In this study, we developed and characterized a PIM membrane type, based on polymer supports PVDF and PVP with NTA as extractive agent. Then, this membrane was adopted to perform the various experiments relating to the oriented process of the facilitated extraction and recovery of $\mathrm{Cr}(\mathrm{VI})$ and $\mathrm{N}(\mathrm{II})$ ions substrates from simulated aqueous textile solutions. The established models for this oriented process were validated, macroscopic and microscopic parameters (permeability $\mathrm{P}$, initial flux $\mathrm{J}_{0}$, association constant Kass, apparent diffusion coefficient $\mathrm{D}^{*}$ ) for this facilitated extraction process of the two substrates across the elaborated membrane were determined.

For this process, the PIM membrane consisting of PVDF as a polymer base and NTA as extracting agent was found to be the most effective for the extraction process of $\mathrm{Ni}(\mathrm{II})$ compared to its counterpart $\mathrm{Cr}(\mathrm{VI})$.

The overall data indicate that the oriented process mechanism relating to the diffusion through this membrane type (PIMs) for the facilitated extraction and removal of $\mathrm{Cr}(\mathrm{VI})$ and $\mathrm{Ni}(\mathrm{II})$, is carried out according to successive jumps from one fixed site to another of the extractive agent in the membrane phase.

Funding: This work was supported by the Ministry of Higher Education and Scientific Research (MESRSFC) and the National Center of Scientific and Technical Research (CNRST). [PPR2 project]. 


\section{References}

[1] V.M. Boddu, K. Abburi, J.L. Talbott, E.D. Smith, Removal of Hexavalent Chromium from Wastewater Using a New Composite Chitosan Biosorbent, Environ. Sci. Technol. 37 (2003) 4449-4456.

[2] F. Fu, R. Chen, Y. Xiong, Application of a novel strategy-Coordination polymerization precipitation to the treatment of $\mathrm{Cu}^{2+}$-containing wastewaters, Sep. Purif. Technol. 52 (2006) 388-393.

[3] F. Fu, H. Zeng, Q. Cai, R. Qiu, J. Yu, Y. Xiong, Effective removal of coordinated copper from wastewater using a new dithiocarbamate-type supramolecular heavy metal precipitant, Chemosphere 69 (2007) 1783-178.

[4] M.K. Doula, Simultaneous removal of $\mathrm{Cu}, \mathrm{Mn}$ and $\mathrm{Zn}$ from drinking water with the use of clinoptilolite and its Fe-modified form, Water Res. 43 (2009) 3659-3672.

[5] A. Jusoh, L.Su. Shiung, N. Ali, M.J.M.M. Noor, A simulation study of the removal efficiency of granular activated carbon on cadmium and lead, Desalination 206 (2007) 9-16.

[6] S.Y. Kang, J.U. Lee, S.H. Moon, K.W. Kim, Competitive adsorption characteristics of $\mathrm{Co}^{2+}, \mathrm{Ni}^{2+}$, and $\mathrm{Cr}^{3+}$ by IRN-77 cation exchange resin in synthesized wastewater, Chemosphere 56 (2004) 141-147.

[7] J. Landaburu-Aguirre, V. García, E. Pongrácz, R.L. Keiski, The removal of zinc from synthetic wastewaters by micellar-enhanced ultrafiltration: statistical design of experiments, Desalination 240 (2009) 262-269.

[8] G. Chen, Electrochemical technologies in wastewater treatment, Sep. Purif. Techno. 38 (2004) 11-41.

[9] M. Hlaïbi, N. Tbeur, A. Benjjar, O. Kamal, L. Lebrun, Carbohydrate-resorcinarene complexes involved in the facilitated transport of alditols across a supported liquid membrane, J. Membr. Sci 377 (2011) 231-240.

[10] E.H. ElAtmani, A. Benelyamani, H. Mouadili, S. Tarhouchi, S. Majid, K. Touaj, L. Lebrun, M. Hlaibi, The oriented processes for extraction and recovery of paracetamol compound across different affinity polymer membranes Parameters and mechanisms, Eur. J. Pharm. Biopharm. 126 (2018) 201-210.

[11] H. Mouadili, S. Majid, O. Kamal, E.H. ElAtmani, K. Touaj, L. Lebrun, M. Hlaibi, New grafted polymer membrane for extraction, separation and recovery processes of sucrose, glucose and fructose from the sugar industry discharges, Sep. Purif. Technol. 200 (2018) $230-241$.

[12] M. Hor, A. Riad, A. Benjjar, L. Lebrun, M. Hlaïbi, Technique of supported liquid membranes (SLMs) for the facilitated transport of vanadium ions $\left(\mathrm{VO}^{2+}\right)$, Desalination 255 (2010)188-195. 